\title{
MEASURING THE AMOUNT OF LEAD IN INDOOR DUST: LONG-TERM DUST-FALL ACCUMULATION IN PETRI DISHES (A PILOT STUDY)
}

John Wlodarczyk, Medical Statistician

Kim Jardim-Surman, Research Assistant

Randall Robertson, Computer Programmer

Rosemary Aldrich, Public Health Physician

Ruth Toneguzzi, Clinical Nurse Specialist

Michael J Hensley, Director

Newcastle Environmental Toxicology Research Unit

(NETRU)

Charles Gruszynski, Scientist, Clinical Chemistry, HAPS

Brian Gulson, Scientist, Macquarie University / CSIRO

ead from dust is potentially the major contributor to

blood lead levels in children living in urban

environments in Australia ${ }^{1}$ and is likely to make a

substantial contribution to blood lead levels of children living in the vicinity of lead smelters. We undertook a trial of measuring dust in petri dishes to estimate the long-term flux of lead in indoor dust.

Conventional methods of assessing risk from lead exposure have concentrated on outdoor sampling of lead in soil and in air. Although these pathways may be important in delivering lead to a child's house, the most likely source of directly ingestible lead is dust that settles inside homes.

Risk to neurological development is assumed to be greatest in toddlers and preschool children who spend much of their time indoors. The natural actions of putting into the mouth hands, toys and other objects carrying dust are unavoidable in this age group. The risk associated with these actions is more relevant to potential interventions than measures of outdoor lead concentrations.

Among the methods used for measuring lead in indoor dust are passive wipe methods, vacuum cleaners and long-term dust-fall accumulation. Passive wipe methods (wiping a surface with a cloth) have limitations in that it is technically difficult to remove the lead from the cloth for analysis, and in that the cloths do not work well on rough surfaces (such as carpets). Vacuum cleaners need to be especially designed to pick up fine particulates and must be mains powered $d^{2.3}$. Neither of these methods allows an assessment of the time taken for the dust to accumulate.

In Australia, Gulson has pilot-tested a method for measuring dust-fall accumulation, using petri dishes. ${ }^{4}$ In his study the petri dishes were left in suburban houses in Sydney and Broken Hill for three months. The method was useful for measuring total lead deposition (load) and sufficient dust was collected for speciation (that is, detailed analysis of lead isotopes and scanning electron microscopy). The isotopic fingerprints (identifying sources of lead) in the dust found in petri dishes were strongly correlated with the isotopic fingerprints found in children's blood.

Australia's second largest lead smelter, operated by Pasminco Metals-Sulphide, is in the suburb of Boolaroo on the northern shores of Lake Macquarie. Boolaroo and the adjacent suburbs of Argenton and Speers Point developed around the smelter. The site gradually expanded its works so that now the closest house is only $150 \mathrm{~m}$ from the main stack.
For years the community has been concerned about the effects of lead pollution in the area. The aims of this pilot study were to adapt and trial the petri dish method of measuring long-term dust accumulation and to quantify the amount of lead in dust falling on interior surfaces.

\section{METHODS}

Selection and setting up of petri dishes

Fifteen households were recruited for the pilot study - nine from North Lake Macquarie (Boolaroo and Speers Point) and six from other urban areas of the Hunter region.

The households at North Lake Macquarie were a convenience sample willing to cooperate with the study plan. The nearest house in the sample was $400 \mathrm{~m}$ from the lead smelter stack. Other households were recruited at approximately $100 \mathrm{~m}$ intervals from the smelter stack.

The six households from outside the North Lake Macquarie area were made up of volunteers from staff members of the Newcastle Environmental Toxicology Research Unit (NETRU). The houses were in the industrial and inner-city areas of Mayfield and Cooks Hill, and the suburban areas Adamstown, Charlestown and New Lambton.

Four petri dishes were placed in each house, in the four most-used rooms. The dishes were placed $0-2 \mathrm{~m}$ from floor level on objects where the dishes would not be disturbed and would not be obstructed from dust fall. The position of each dish was recorded. The dishes were secured with a piece of plasticine on the base of the dish after the mounting surface had been wiped with a tissue.

The dishes were left in the houses for 5-12 weeks. They were removed, placed flat in individual airtight bags, secured in a box and transported to the laboratory for analysis

\section{Laboratory methods}

Polystyrene petri dishes $85 \mathrm{~mm}$ in diameter were prepared by the Trace/Toxic Element Unit, Division of Clinical Chemistry, Hunter Area Pathology Service. Petri dishes were soaked overnight in an alkaline detergent, thoroughly rinsed with deionised water, then soaked for a further 48 hours in ultra-pure 2 per cent nitric acid. Finally, the petri dishes and their lids were removed from the acid, rinsed three times with ultra-pure deionised water (resistivity $>18 \mathrm{M}$ ), and dried in a low temperature drying oven. When dry, each dish (with its corresponding lid) was numbered and accurately weighed

Assays of lead content were carried out in accordance with draft international standard ISO/DIS 9855, except that the acids were used in a concentration of $7 \mathrm{M}$ nitric acid and $6 \mathrm{M}$ hydrochloric acid. This procedure is based on nitric acid and hydrochloric acid digestion and final determination by graphite furnace atomic absorption spectrometry.

If the amount of collected dust was sufficient to allow accurate weighing, the lead content was reported as:

- concentration, in $\mu \mathrm{g} \mathrm{Pb} / \mathrm{gm}$ dust

- loading, in $\mu \mathrm{g} \mathrm{Pb} / \mathrm{area}\left(\mathrm{m}^{2}\right)$

flux, in $\mu \mathrm{g} \mathrm{Pb} / \mathrm{area}\left(\mathrm{m}^{2}\right)$ per month 
If insufficient dust was collected to allow accurate weighing, only lead loading and flux were reported.

\section{Statistical analysis}

Lead loading and concentrations were approximately log normally distributed and were transformed accordingly for analysis. Since the petri dishes were left out for various periods, loading estimates were firstly standardised to a four-week period: thus, if the dish was placed for five weeks, the flux was calculated as four-fifths of that measured.

Initial graphical review of data also highlighted a relationship between the height of the dish from the floor and the lead loading: the lower the dish, the higher the lead level. In order to standardise for differences in height, a linear regression model was used to estimate the relationship between $\ln$ lead loading and height. This regression equation was then used to standardise loading measures to a height of $1 \mathrm{~m}$.

Therefore, the final results are presented as $\mu \mathrm{g}$ lead $/ \mathrm{m}^{2}$ per month at $1 \mathrm{~m}$. The arithmetic average of results from each house is also presented.

The relationship between distance from the smelter and lead flux was estimated by simple linear regression.

\section{RESULTS}

Lead flux in relation to distance from the smelter The main results are presented in Figures 1 and 2. Figure 1 shows a scattergram of the lead flux ( $\mu \mathrm{g} \mathrm{lead} / \mathrm{m}^{2}$ per month) levels for each dish, while Figure 2 shows a scattergram of the average lead flux ( $\mu \mathrm{g}$ lead $/ \mathrm{m}^{2}$ per month) for each household. The results for houses in North Lake Macquarie are shown on the left of both scattergrams, plotted against distance from the smelter. The results for houses from other Newcastle areas are shown at the right of the scattergrams. There was a clear trend towards decreasing lead flux with distance from the smelter $\left(P<0.0001, r^{2}=0.94\right)$. The average lead flux levels for houses $600 \mathrm{~m}$ to $1 \mathrm{~km}$ from the smelter were approximately 30 per cent of those from houses $400-600 \mathrm{~m}$ from the smelter. The average lead flux for houses in North Lake Macquarie was 1,148 $\mu \mathrm{g} \mathrm{lead} / \mathrm{m}^{2}$ per month.

The houses from other Newcastle areas had an average lead flux of $237 \mu \mathrm{g}$ lead $/ \mathrm{m}^{2}$ per month. Interestingly, one house was extensively repainted during the study, which included sanding back very old paint. The lead flux results for this house were considerably above those for other areas of Newcastle and comparable to those in North Lake Macquarie. The second highest readings came from a house at Mayfield between two major highways.

\section{DISCUSSION}

This study has shown the potential usefulness of using petri dishes to measure long-term dust accumulation in a community setting. The method was relatively simple and caused minimal inconvenience to householders. The results obtained over 4-12 weeks appear to reflect the gradients in air and soil lead concentrations in the vicinity of a lead smelter. The lower levels in Newcastle homes away from the smelter are consistent with less lead exposure.

The method also appeared to be sensitive to sources of lead such as sanding leaded paint during renovations.

\section{FIGURE 1}

Scattergram of log lead flux, standardised to a four-week period and $1 \mathrm{~m}$ height: individual dishes

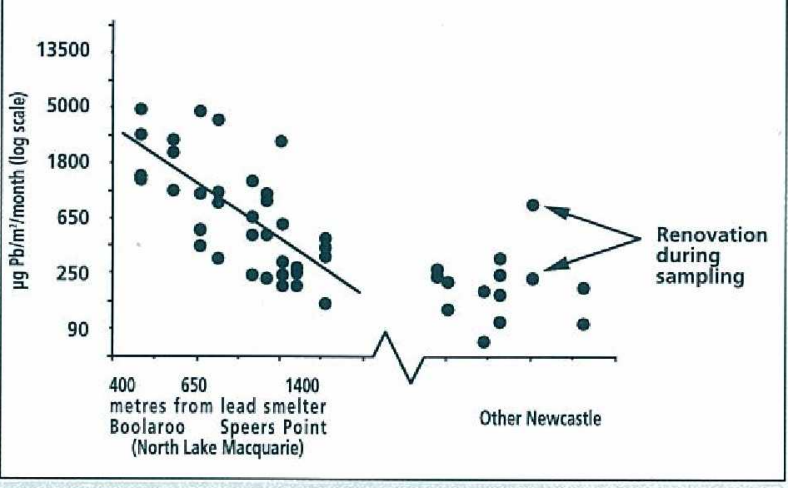

\section{FIGURE 2}

Scattergram of log lead flux, standardised to a four-week period and $1 \mathrm{~m}$ height: mean for each participant



Although the study was not designed to include an investigation of the effects of leaded paint on lead loading, the level for the one house known to have been renovated during the study was markedly higher than those for other houses in the Newcastle area, and deserve further investigations.

The petri dish method has the advantage of measuring lead loading and flux in addition to concentration, that is, it gives an estimate of the total amount of lead accumulating in a home over a specific period in addition to the amount of lead in each gram of dust.

One way to conceptualise the difference between lead loading and lead concentration is to consider the effect of cleaning a house with a wet cloth. While this would reduce the total amount of lead available for ingestion by reducing the amount of dust in the house, it would not alter the concentration of lead in the dust remaining. The lead loading measure done after cleaning would reflect the lower levels of lead remaining. 


\section{Lead in dust and soil from day-care centres}

\section{Continued from page 95}

\section{ACKNOWLEDGMENTS}

We thank: Macquarie University for financial support for this study under the Macquarie University Research Grants Scheme; Ms Ginie Udy of the Uniting Church Children's Services Forum for access to the day-care centres; the coordinators of the centres for their assistance; Professor Barry Batts for access to the ICP-AES; and Graeme Waller for the surface wipe digestion method.

1. National Center for Lead Safe Housing, Maryland. Guidelines for the evaluation of lead-based paint hazards in housing. February 1995. 2. Bawden-Smith J, McAnulty J, Bek M. Lead exposure at a school for children with developmental disabilities. NSW Public Health Bulletin 1995; 6(11):124-6.

3. Fett MJ, Mira M, Smith J et al. Community prevalence survey of children's blood lead levels and environmental lead contamination in inner Sydney. Med J Aust 1992; 157:441-5.

4. Gulson BL, Jameson CW, Mahaffey KR, Mizon KJ, Korsch MJ, Vimpani G. Pregnancy increases mobilisation of lead from maternal skeleton. J Lab Clin Med 1997; 130:51-62.

5. National Research Council. Measuring lead exposure in infants, children, and other sensitive populations. Washington DC: National Academy Press, 1993.

6. Chiaradia M, Gulson BL, Mizon KJ, James M, Jameson CW, Johnson D. Identification of secondary lead sources in the air of an urban environment. Atmos Environ 1997; 31:3511-21.

7. NSW Government Lead Issues Paper. Sydney: Environment

Protection Authority, 1993.

8. Gulson BL, Davis JJ, Bawden-Smith J. Paint as a source of recontamination of houses in urban environments and its role in maintaining elevated blood leads in children. Sci Total Environ 1995 maintainin

164:221-35.
9. Gulson BL, Davis JJ, Mizon KJ, Korsch MJ, Bawden-Smith J. Sources of lead in soil and dust and the use of dust fallout as a sampling medium. Sci Total Environ 1995; 166:245-62.

\section{EDITORIAL NOTE}

Lead is a ubiquitous contaminant of the urban environment. Children are at greatest risk of exposure and harm from absorption of environmental lead by virtue of their behaviour, their metabolism and the sensitivity of the developing nervous system to the toxic effects of lead. Lead in paint and lead additives in fuel are two sources of lead exposure in urban areas. This study confirms that lead is readily detected in the home and play environment of many children in NSW. A recent study showed that average blood lead levels in NSW preschool children were 5 to $7 \mu \mathrm{g} / \mathrm{dL}$, with less than 25 per cent of inner-city children being above the goal for blood lead of $10 \mu \mathrm{g} / \mathrm{dL}^{1}$. This is an improvement since $1992^{2}$. Reductions in the proportion of cars using leaded fuel and in the the lead added to that fuel have reduced exposure. A study in Sydney showed that traffic flow near a child's home was a more important determinant of blood lead level than the traffic flow at the child's child-care centre ${ }^{3}$. These results do not detract from the need for efforts to reduce exposure to environmental lead, such as those now being coordinated by the Lead Reference Centre.

1. Mira M, Bawden-Smith J, Causer J, et al. Blood lead concentrations of preschool children in Central and Southern Sydney. Med J Aust 1996; 164:399-402.

2. Fett M, Mira M, Smith J, et al. Community prevalence survey of children's blood lead levels and environmental lead contamination in inner Sydney. Med J Aust 1992; 157:441-445.

3. Cowie C, Black D, Fraser I. Blood lead levels in preschool children in eastern Sydney. Aust NZ J Public Health 1997; 21:755-760.
Measuring the amount of lead in indoor dust

\section{Continued from page 93}

Thus, the petri dish method can be used as a measure of recontamination, allowing individuals and health authorities to assess the effectiveness of abatement strategies.

Although no single method has yet been established as a standard for measuring indoor lead exposure, the long-term dust-fall accumulation method has advantages: it has low cost, does not require a power source, causes minimal inconvenience to the householder, does not involve noise, can be measured over a specific period, and cannot be biased by the householder cleaning the house before a sample visit ${ }^{4}$

The disadvantages of the method are the potential for disturbance or contamination and the time delay to obtain a measurement. In our study only one dish was lost and there were no overt signs of contamination.

Further evaluation of the technique to quantify the direct relationship between lead loading and blood lead levels is under way in North Lake Macquarie and Broken Hill. Our pilot study has shown that the method provides a valuable indicator of comparative trends in lead exposure over time and between areas.

1. Royal Melbourne Institute of Technology. Reducing Lead Exposure in Australia: Risk Assessment and Analysis of Economic, Social and Environmental Impacts. Canberra: Australian Government Publishing Environmental Impacts. Canberra. Australian Government Publishin Service, 199

2. Rinehart R, Rogers J, Vendetti M. Wipe/vacuum lead in house dust sampling, draft report to US EPA, 1993.

3. Jacobs DE. Guidelines for evaluation and control of lead paint hazards in housing. The National Centre for Lead-Safe Housing for US Department of Housing and Urban Development, 1994

4. Gulson BL, Davis JJ, Mizon KJ, Korsch MJ, Bawden-Smith J. Sources of lead in soil and dust and the use of dust fallout as a sampling medium. Submitted to Sci Total Eviron 1995; 166:245-262.

\section{Update on lead-related activities}

\section{Continued from page 99}

In June 1997, \$4.6 million was received from the NSW Health Department, the NSW Environment Protection Authority and Pasminco Metals-Sulphide for ongoing remediation.

\section{NORTHERN SYDNEY AREA PUBLIC HEALTH UNIT}

Local Government Environmental Health Officers were invited to a regional workshop on roles and responsibilities for lead hazard management conducted by the Lead Reference Centre and the Northern Sydney Area Public Health Unit on 9 December 1997 at Macquarie Hospital, North Ryde. Representatives from local authorities within the area, NSW Environment Protection Authority, WorkCover and Environmental Health Officers from the NSAHS Public Health Unit attended.

Documents distributed included Local Government Lead Management and Guidelines for Environmental Health Officers in managing cases of Elevated Blood Lead Levels. The aim of of the workshop was to provide information about lead hazards and the powers available to deal with lead problems. The outcomes of the day were an awareness of the responsibility of local government in the approval of building applications, procedures to be recommended for building renovations and case investigation protocol. 